This paper is published in the open archive of Mid Sweden University

DIVA http://miun.diva-portal.org

with permission of the publisher

Citation for the peer-reviewed published paper:

Svensson B, Vesterlind E, Höglund H. Frictional properties of native and chemically modified birch wood. ; Nordic Pulp \& Paper Research Journal. $2007 ; 22(3): 325-330$.

URL to article at publishers site:

http://dx.doi.org/10.3183/NPPRJ-2007-22-03-p325-330 


\section{Frictional properties of native and chemically modified birch wood}

Birgitta A. Svensson, Eva-Lotta Vesterlind and Hans Höglund, Mid Sweden University, Sundsvall, Sweden

KEYWORDS: Birch, Friction, Mechanical pulping, CTMP, Sodium sulfite, Sodium hydroxide, Wood extractives, Energy consumption

SUMMARY: The chemithermomechanical pulping of hardwoods, e.g. birch, has attracted increasing interest in the past decade. Chip pretreatment, i.e. chemical impregnation and preheating done when birch chemithermomechanical pulp is produced, affects energy consumption during refining; this study found that frictional forces may be an important parameter in this respect. This study investigates friction between both native and chemically treated birch and a smooth steel surface under simulated chip-refining conditions (hot saturated steam, high sliding speed). The coefficient of friction peaks at approximately $115^{\circ} \mathrm{C}$ for both native and extracted birch. It was shown that sulfonating native birch decreased its coefficient of friction over the temperature range investigated $\left(100-170^{\circ} \mathrm{C}\right)$. The coefficient of friction had a broad and flat peak in the $130-150^{\circ} \mathrm{C}$ temperature interval for the specimens treated with $3 \%$ sodium sulfite at $\mathrm{pH}$ 13.5. Furthermore, it was clear that $\mathrm{pH}$ had a profound influence on the coefficient of friction. A high $\mathrm{pH}$ lowered the coefficient of friction, likely due to well lubricated contacts. The friction arising between birch (Betula verrucosa) and steel was shown to be higher than that between spruce (Picea abies) and steel. The higher stiffness and density of the birch wood, together with a more porous bulk structure leading to rough test surfaces, are some factors possibly accounting for these high friction coefficients. Also, the differences in the amount and composition of the extractive substances in birch and spruce may contribute to the differing frictional behaviors of these species.

\section{ADDRESS OF THE AUTHORS: Birgitta Svensson (birgitta.svensson@miun.se), Eva-Lotta Vesterlind (eva-lotta.vesterlind@miun.se) and Hans Höglund (hans.hoglund@miun.se): Mid Sweden University, Fibre Science and Communication Network (FSCN), Department of Natural Sciences, SE-851 70 Sundsvall, Sweden. Corresponding author: Birgitta Svensson}

Mechanical pulp is traditionally produced from softwood species, typically spruce but to some extent also pine (Sundholm 1999). In recent decades, various hardwoods (mainly aspen) have become important on the world market in the form of chemithermomechanical pulps (CTMP). This marks a great advance for the high yield pulping industry, as it has allowed the development of pulps with new quality profiles. However, research into the fundamental aspects regarding chemimechanical pulping of hardwoods has regretfully fallen behind (Granfeldt 2005). CTMP processes originally developed for spruce have now in practice been adopted for different hardwoods species. To accommodate hardwoods, adjusted operating conditions are usually used, for example, altered chemistry, a lower refining tempera- ture (for printing grades), and the use of more suitable refiner segments (e.g. Turbine ${ }^{\mathrm{TM}}$ segments) (Vikman et al. 2003). More fundamental knowledge of the response of various hardwoods to mechanical and chemical treatment would considerably increase our chances of improving these process efficiencies. In Scandinavia, aspen is by far the most frequently used wood species for CTMP production, while birch is a somewhat neglected resource when it comes to producing high-yield pulp.

The major difference between the conditions for manufacturing softwood versus hardwood CTMP is the different chemical treatment hardwood chips require prior to refining. By impregnating hardwood chips with sodium sulfite and alkali, the wood can be refined using a reduced amount of energy (Granfeldt and Suhonen 2003). Alkali softens the hardwood by chemically modifying the fiber walls, causing the fibers to swell. Besides decreased specific energy consumption, there is an apparent increase in strength properties as the yield and bulk decrease (Wegner 1982; Jackson et al. 1984, 1985; Janson and Mannström 1981; Granfeldt et al. 2001; Granfeldt and Suhonen 2003). The added sodium sulfite, which also helps soften the fibers, has a slight bleaching effect and a positive effect on the shives content. Alkaline peroxide mechanical pulping (APMP) or the more novel pre-conditioning refiner chemical (P-RCTM) approach are other pulping systems that are sometimes preferred (Bohn and Sferrazza 1989; Xu 1999, 2001). APMP is a refining process which uses alkaline peroxide liquor in impregnating the wood chips; however, this process is not further discussed in this paper.

It has previously been shown that by pre-heating birch chips to a high temperature $\left(>140^{\circ} \mathrm{C}\right)$ in a CTMP process prior to refining, it is possible to produce a bulky pulp using less energy than when a lower temperature is used (Vesterlind and Höglund 2005; Vesterlind et al. 2005). This lower energy consumption is partly assumed to reflect a decrease in yield. However, as temperature affects the viscoelastic/plastic properties of wood considerably, it is likely that frictional properties and altered stiffness properties also affect the energy needed to refine to a given freeness.

During refining, friction forces arise both between the refiner plates and the fiber material and in the fiber material itself (in the fiber-fiber contacts). It is indicated in calculations based on fracture mechanical data that only part of the actual energy consumed during refining is used to create fracture surfaces (Koran 1980; Marton et al. 1981). Much of the supplied energy is thus consumed in hysteresis losses and processes that mainly develop the fiber properties further; friction forces are probably the most important agents in these processes. Elegant equations describing the flow and mechanical treatment of 
pulp in chip refiners have been derived (Miles and May 1990), equations that incorporate both the tangential and radial coefficients of friction. These coefficients are, however, kept as constants for various reasons. The tangential coefficients of friction are set to 0.75 , based on refining trials in an atmospheric pilot refiner, while the radial coefficients of friction are set to 0.25 , based on measurements of the sliding friction of wet wood over steel (Atack and May 1958). However, the use of high temperature and saturated steam could potentially complicate the scenario significantly, since friction forces are always affected by the surrounding environment. Therefore, friction coefficients that change with temperature could partly explain the reduced energy consumption occurring when birch CTMP was produced with an increased pre-heating temperature.

A laboratory-scale friction tester (TT2000) was custom-designed and built at the Mid Sweden University, Sweden and is described in Svensson et al. (2003). In the friction tester, the environmental conditions specific to a chip refiner in a TMP or CTMP process are simulated by combining high temperature, a saturated steam atmosphere, and a high sliding speed. By using the TT2000 it was examined how the friction between softwoods (Picea abies and Pinus radiata) and a smooth steel disc changed with temperature (Svensson et al. 2006).

The present study used the TT2000 friction tester to produce new results regarding the effects on birch/steel friction of various chemical treatments relevant to the CTMP process. The differences in friction between birch (Betula verrucosa) and spruce wood (Picea abies) are also discussed, as are the effects of removing the extractive substances (soxhlet extractions) from the wood matrixes.

\section{Materials and Methods}

The raw materials were taken from sapwood sections of birch and spruce. Cubic specimens, $12 \times 12 \times 12 \mathrm{~mm}$, were prepared according to the method described in Svensson et al. (2003) and Svensson et al. (2006). How the specimens were cut and the sliding direction of the specimens are shown in Fig 1.

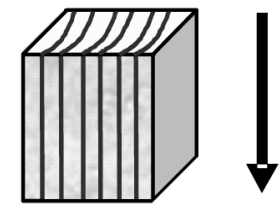

Sliding direction on tangential test surface

Fig 1. Schematic illustration showing the tangential test surface and the sliding direction during measurement.

Studies were performed on native as well as extracted wood; this was done by means of soxhlet extraction with acetone $(8 \mathrm{~h})$, dichloromethane $(16 \mathrm{~h})$, and acetone (16 h). When the specimens had been chemically modified prior to the friction measurements, impregnation was performed in a steam-pressurized vessel for $15 \mathrm{~min}$ at $130^{\circ} \mathrm{C}$ in various concentrations of sodium sulfite and/or sodium hydroxide p.a. supplied by Sigma-Aldrich. The wood-to-liquid ratio was $1: 10$, which was sufficient to avoid lowering the $\mathrm{pH}$ during impregnation due to the dissolution of acetic acid from the wood. After impregna- tion, the specimens were stored in milli-Q water adjusted to the same $\mathrm{pH}$ as the impregnation liquid until the measurements were performed (maximum 2 days). It can be assumed that the reactions with sodium sulfite were ended prior to testing. However, since the specimens were stored in water adjusted to the same $\mathrm{pH}$ as that of the impregnation liquid, reactions due to the added acids or alkali could possibly be expected also during the storage time and during testing. The wood was taken out of the liquid during the measurements. When observed in a stereomicroscope the $\mathrm{pH} 9.5$ specimen surfaces only showed minor changes in topography caused by the impregnation. But, when a reacting liquid of $\mathrm{pH} 13.5$ was used the specimen surfaces had clearly changed (e.g. swelled) as a result of the impregnation. Despite these distortions on the specimens, the surfaces were not trimmed prior to the friction measurements since the wood material was too soft for that. The data regarding the raw material are presented in Table 1.

The surface roughness of the specimens was measured by means of optical profilometry using the MicroProf ${ }^{\mathrm{TM}}$ profilometer (Fries Research and Technology $\mathrm{GmbH}$, Bergisch Gladbach, Germany).

The friction measurements were made and evaluated in the same way and using the same "pin on disc" type of friction tester, the TT2000, as described in Svensson et al. (2003) and Svensson et al. (2006). The friction tests were performed in saturated steam and the same counter surface of smooth steel was used in all measurements. To achieve different testing temperatures $\left(100-170^{\circ} \mathrm{C}\right)$ the steam pressure was set to various levels. The steel disc (SS2333 0.07\% C stainless steel) was ground, annealed, and then polished to achieve an $R_{a}$ value between 0.03 and $0.1 \mu \mathrm{m}$. The relative sliding speed in the tests was 25 $\mathrm{m} / \mathrm{s}$ and the normal load on the specimens was $14 \mathrm{~N}$. Before the first measurement at a new temperature, the steel disc was cleaned with water and acetone and the apparatus was after that heated without any specimen to avoid temperature gradients during friction registration. Then, after each new specimen was placed in the friction tester, the pressure was raised quickly (in $\sim 10 \mathrm{sec}$ ) to 100 $\mathrm{kPa}$ higher than the equivalent temperature chosen for the measurement. The higher temperature was held for $1 \mathrm{~min}$ and then lowered to the desired temperature, which was also held for $1 \mathrm{~min}$, before the specimen was loaded and the friction force was registered. In the figures, each point represents a median value of six measurements of separate specimens; the $90 \%$ confidence intervals are indicated by the shaded areas.

\section{Results and Discussion}

Fig 2 shows the coefficient of friction, $\mu$, registered for native birch and extracted birch from $100^{\circ} \mathrm{C}$ to $170^{\circ} \mathrm{C}$. The curve for the native birch specimens was fairly flat, i.e. the change in friction over the temperature range was quite small. The extracted specimens displayed higher $\mu$ values over the temperature range than did native birch. The largest difference between native and extracted specimens appeared at $100^{\circ} \mathrm{C}$; thereafter the differences gradually reduced. At approximately $150^{\circ} \mathrm{C}$ the measure- 
ments started to cause wear on the extracted wood material and fibers became liberated from the surfaces. At even higher temperatures the wear debris increased in amount and probably acted as a solid lubricant, considerably reducing the friction between the surfaces. This has also been observed in contacts between other viscoelastic materials, such as rubber (Baek and Khonsari 2006).

It could be visually observed during the sliding of the native specimens that thin layers presumably of wood extractives formed at the interface caused lubrication. In the extracted birch specimens, however, most of the extractive substances had been removed, so lubrication from extractives was, if not non-existent, clearly reduced. This may partly account for the higher $\mu$ values of the extracted specimens.

The extraction procedure also affected the wood material in other ways, for example, by increasing the saturated moisture content (see Table 1) and void volume of the wood matrix. The higher level of friction could also partly be due to the higher moisture content, as reported by Svensson et al. (2003), who showed that the coefficient of friction between wood and steel increases with moisture content. One reason for this increase could be a larger contribution to the friction from energy dissipations in the bulk material, because it is softened by the water.

In studying the chemithermomechanical pulping of birch it is interesting to examine the frictional behavior of chemically treated birch wood. Fig 3 shows the coefficient of friction registered for native birch that had been impregnated with $\mathrm{Na}_{2} \mathrm{SO}_{3}$ at $\mathrm{pH} 9.5$ and 13.5 (2\% $\mathrm{NaOH})$. The friction coefficient was fairly constant up to $130^{\circ} \mathrm{C}$ for specimens that had been impregnated without any added alkali, i.e. at $\mathrm{pH} 9.5$. At approximately $130^{\circ} \mathrm{C}$ wear was initiated and at $150^{\circ} \mathrm{C}$ fibers started to come loose from the wood matrix. The curve showing the coefficient of friction of the specimens that had been impregnated at $\mathrm{pH} 13.5$ (with $2 \% \mathrm{NaOH}$ ) had a slightly different profile. The coefficient of friction was initially lower than for the specimens impregnated without additional alkali. However, between $130^{\circ} \mathrm{C}$ and $150^{\circ} \mathrm{C}$ there was a distinct peak at which the friction caused wear, followed by material losses when the temperature exceeded $150^{\circ} \mathrm{C}$. The moisture content of the specimens was essentially the same, approximately $60 \%$ (see Table 1 ). However, there was a considerable difference in the perceived softness of the material when the specimens were removed from the friction tester after measurement. The specimens impregnated at $\mathrm{pH} 13.5$ had rubbery features and were easily irreversibly deformed when removed from the equipment. The specimens impregnated without extra alkali were "softer" than the native specimens, but still not as soft as the $\mathrm{pH} 13.5$ specimens and had lower coefficients of friction over the temperature range studied (cf. Fig 2).

The peak that appears for the specimens impregnated with $3 \% \mathrm{Na}_{2} \mathrm{SO}_{3}$ at $\mathrm{pH} 13.5(2 \% \mathrm{NaOH})$ approximately

ecimens.

Spruce (Picea abies)

Sapwood

rento

$0.38 \quad( \pm 0.03)$

$63.7 \quad( \pm 0.8)$

native

extracted

$68.4 \quad( \pm 1.2)$

native $\quad 1.5 \quad( \pm 0.2)$

after extraction $\approx 0.4$
Birch (Betula verrucosa) Sapwood

$0.63( \pm 0.02)$

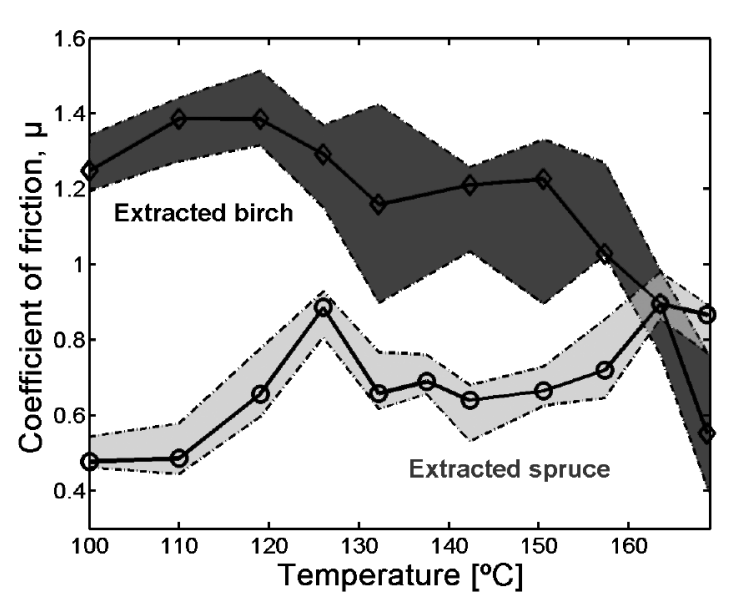

Fig 2. The coefficient of friction, $\mu$, of native and extracted birch as a function of temperature.

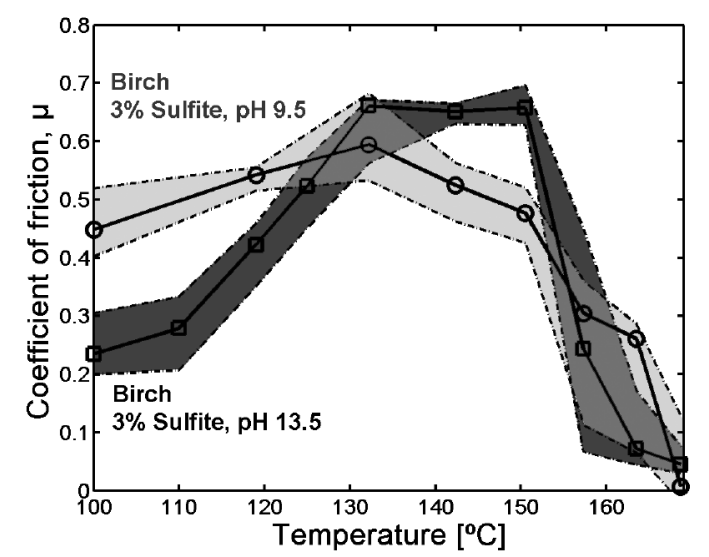

Fig 3. The coefficient of friction, $\mu$, of native birch impregnated with $3 \% \mathrm{Na}_{2} \mathrm{SO}_{3}$ at pH 9.5 and $13.5(2 \% \mathrm{NaOH})$ as a function of temperature.

coincided with the temperature range at which the energy consumption in the manufacturing of birch CTMP started to decline, according to Vesterlind et al. (2005) and Vesterlind and Höglund (2005). These results thus seem to indicate that the frictional forces may be one explanation of the lower energy consumption at high pre-heating temperatures, yield also being cited as an explanation. The above studies also indicated that the shives content became quite high at a very high temperature $\left(170^{\circ} \mathrm{C}\right)$ when the energy input was kept low, despite a comparatively small plate gap. The experimental results produced here indicate that the coefficient of friction is very low at a high temperature, i.e. $170^{\circ} \mathrm{C}$. This suggests that the liberation of material in refining at this high temperature may be mainly thermally accomplished. At such high 


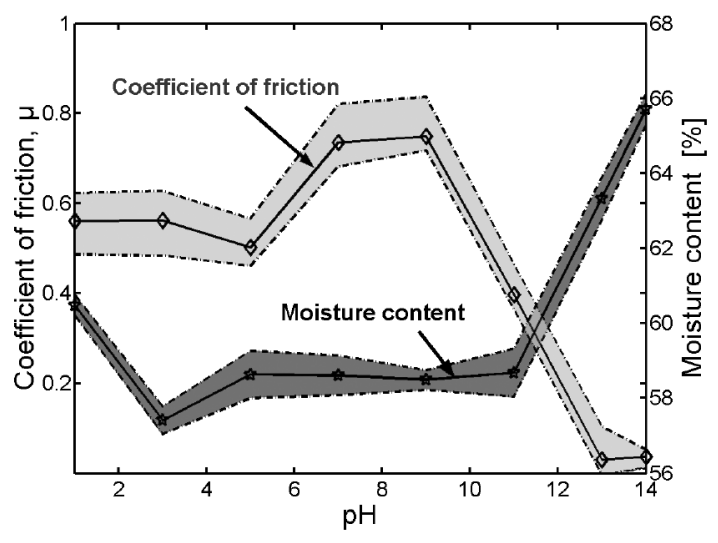

Fig 4. The friction coefficient and moisture content of native birch that had been impregnated with liquid of various $\mathrm{pH}$ levels. Measurements were made in $110^{\circ} \mathrm{C}$ saturated steam.

temperature the lignin matrix, which literally holds the fibers together in the wood material, is softened to such high extent that very little mechanical work is needed to separate the fibers from each other. Of course this is an advantage when discussing the energy consumed in the process. But, it is difficult to refine this pulp further, towards lower freeness levels, since the fiber material does not take any additional load. One explanation to the high shives content at $170^{\circ} \mathrm{C}$ is likely the very low friction forces at this point which are not sufficient for complete defibration to occur; enough energy cannot be transferred to the fiber material.

The only difference in treatments between the specimens used for the two curves in Fig 3 is the alkalinity of the impregnation liquid. Considering the impact alkalinity had on the perceived viscoelastic/plastic properties of the wood, it was interesting to see what would happen to the frictional forces when impregnation was done with liquids of various $\mathrm{pH}$ values. Fig 4 shows the coefficient of friction as a function of $\mathrm{pH}$ for measurements made at $110^{\circ} \mathrm{C}$, that is, approximately where the difference between the two curves in Fig 3 was the largest. Fig 4 also shows the moisture content of the specimens. As can be seen, the moisture content of the specimens was fairly constant up to a $\mathrm{pH}$ of approximately 11 , after which it increased. This could be because when the birch specimens were treated with alkali, some of the wood components (mainly the hemicelluloses) were chemically modified, increasing the fiber swelling (Katz et al. 1981), that is, the moisture content of the wood increased. Another likely explanation is the lower yield of the specimens. The specimens could hold additional water in the new cavities formed when material was dissolved from the wood matrix.

Fig 4 shows that the coefficient of friction peaks for specimens impregnated with liquid of $\mathrm{pH} 7$ and 9, whereas it decreases at $\mathrm{pH}$ values higher than 10. As previously discussed, more water in the bulk material could increase the frictional forces due to softening; however, this is not the case here. Besides affecting the bulk material, alkali also affects the wood-steel interface, which probably causes full-film or mixed lubrication with small frictional forces as a consequence. This is unlikely solely to be lubrication resulting from high alkalinity, since when comparing values at $110^{\circ} \mathrm{C}$ from Fig 3 with those from Fig 4, there are marked differences due to the sodium

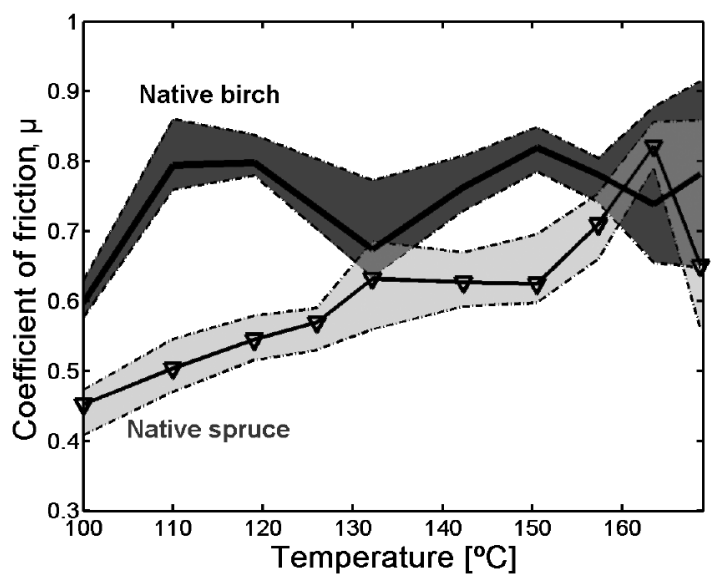

Fig 5. The coefficient of friction, $\mu$, of native birch and native spruce as a function of temperature.

sulfite use presented in Fig 3. It was not determined what components the lubricating layer contained. However, various extractives were certainly present on the surface, some of which were probably modified by the alkali treatment. It is not unlikely that changes in the $\mathrm{pH}$ of the impregnation liquid affected the physical characteristics, such as the viscosity and tackiness, of these components.

The results presented in Figs 2-4 show that the frictional behavior can be related to the temperature at which the measurement is performed. In the low temperature range, $100-110^{\circ} \mathrm{C}$, it is possible that the coefficient of friction was governed by interfacial interactions, as the wood was not significantly softened. The sensitivity to interfacial phenomena such as lubrication should therefore be prominent in this region. In the middle region, $\sim 110-150^{\circ} \mathrm{C}$, the bulk material of the wood was softened to various degrees. The coefficient of friction will then reflect the balance between energy dissipation into the bulk material, macroscopic deformations on the surface, and the influence of other surface phenomena. The beginning of formation of wear debris $\left(\sim 150^{\circ} \mathrm{C}\right.$ in Figs 2 and 3$)$ marks the point at which the energy transferred into the specimen is sufficient to cause rupture. At even higher temperatures, $>150^{\circ} \mathrm{C}$, the measurements were made more complicated by the presence of wear debris. As the temperature increased the amount of wear debris increased, the viscosity of the debris decreased as did the measured friction.

As previous studies with spruce have been made using the same equipment, it was of interest to examine the different behavior of the two species. Fig 5 shows the coefficient of friction, $\mu$, registered for native birch and native spruce from $100^{\circ} \mathrm{C}$ to $170^{\circ} \mathrm{C}$. Native spruce had a lower coefficient of friction than birch did over nearly the entire temperature range investigated. The difference was more pronounced in the low temperature range, as the coefficient of friction increased with increased temperature for native spruce unlike for native birch.

There are a few possible explanations as to why the frictional forces are higher for native birch than for native spruce. Fig 6 presents surface roughness profiles and $\mathrm{R}_{\mathrm{a}}$ values for the specimens. Stereo microscope images of tangential cuts of spruce (bottom right) and birch (bottom left) are also shown. As seen in the figure, the test surfaces of native birch were much rougher than those of spruce. The rougher surface of the birch specimens originates 

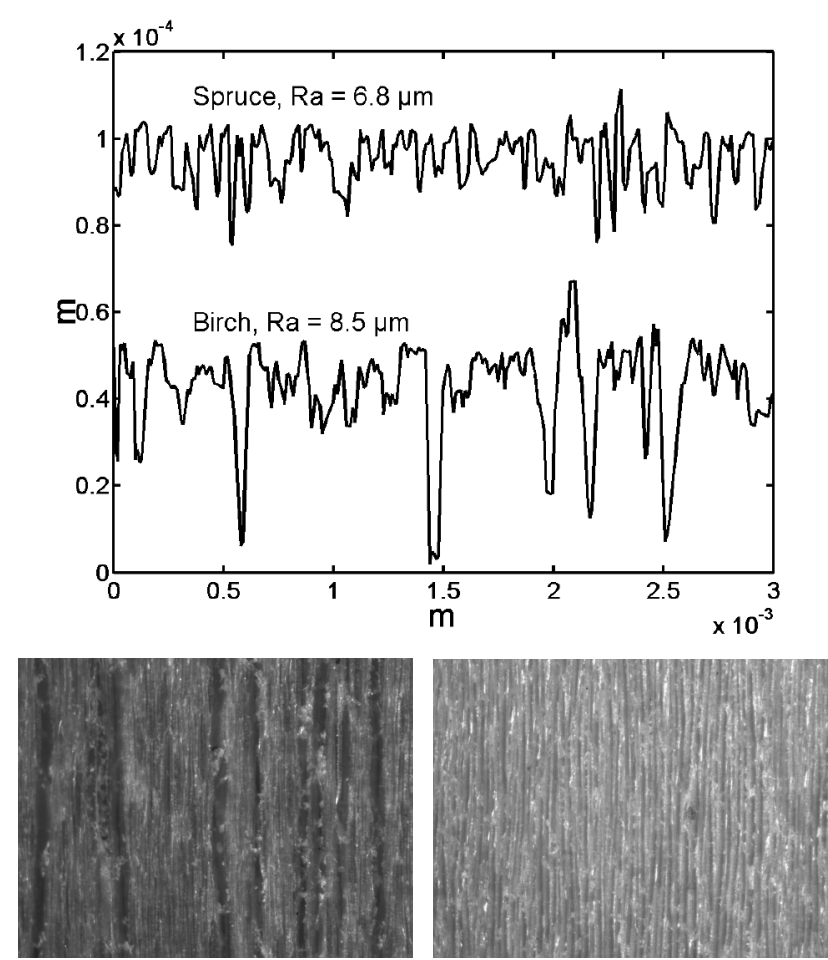

Fig 6. At the top, two surface roughness profiles of the specimens and their $R_{a}$ values, obtained by optical profilometry, are shown. At the bottom are stereo microscope images, obtained at equal magnification, of tangential cuts of birch (bottom left) and spruce (bottom right).

from a more porous wood matrix with vessels that are used for transporting water and nutrients in the living birch tree. In spruce wood the water is transported through the wood fibers and through pores in the fiber walls, i.e. there are no vessels.

Table 1 shows that the amount of extractives in the birch wood $(2.0 \%)$ differed from the amount of extractives in spruce (1.5\%). Spruce wood contains resin channels that are oriented both vertically and radially in the wood matrix, so some of the resin channels in the wood specimens will be directed vertically against the steel disc. Birch wood does not contain these special resin channels; instead the extractives are contained and transported in rays comprising parenchyma cells, making the extractives less physically accessible. This means that during these measurements, layers or films of wood extractives at the interface likely formed more easily with spruce than with birch specimens. The greater smoothness of the spruce test surfaces could also have made it easier to establish and sustain an effective lubricating regime between the specimen and the disc. The rougher test surfaces of birch were probably more difficult to lubricate with the available amount of extractives. This could partly explain why the birch specimens displayed higher $\mu$ values over the entire temperature range.

Svensson et al. (2006) proposed that the increase in friction coefficient that occurred for the native spruce specimens as the temperature was raised could be an effect of decreased lubrication; at higher temperatures the extractives are more likely to desorb, and some components could possibly even evaporate. The difference in extractive composition between the species may be important from this perspective.

Extraction caused the coefficient of friction between birch and steel to increase radically over the entire temperature range, except at very high temperatures (i.e.

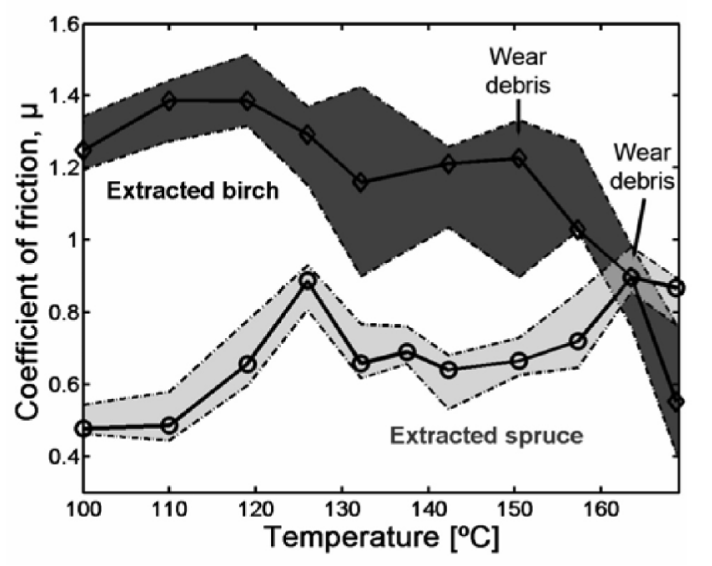

Fig 7. The coefficient of friction, $\mu$, of extracted birch and spruce as a function of temperature.

$\sim 170^{\circ} \mathrm{C}$, cf. Fig 2). Fig 7 shows the coefficient of friction, $\mu$, registered for extracted birch and extracted spruce from $100^{\circ} \mathrm{C}$ to $170^{\circ} \mathrm{C}$. The figure shows that the extracted birch wood reached a much higher friction level than extracted spruce did. There were also larger differences in friction between native and extracted specimens of birch than between native and extracted spruce.

The extractives content of native birch listed in Table 1 is $2.0 \%$ compared to $1.5 \%$ for spruce. During the extraction procedure more material is apparently resolved from the birch specimens, since after specimen extraction the extractives content is approximately the same for the two species. The moisture content listed in Table 1 is the saturated moisture content. The moisture content after extraction increased by $9 \%$ units for birch, versus only $4 \%$ for spruce. More water in the wood matrix means a more porous and softer structure. In Svensson et al. (2006) the same phenomenon was shown for extracted pine (Pinus radiata), i.e. very large differences in friction between native and extracted wood as well as large differences compared to spruce.

It was then proposed that increased friction due to extraction may be an effect of the following: 1) less lubrication from extractives, 2) increased interfacial interactions due to a less contaminated wood surface, and/or 3) increased energy dissipation into a more softened bulk material. The higher level of friction could then also be explained by the results of Svensson et al. (2003), which indicate that the coefficient of friction between wood and steel increases with increasing moisture content.

The softening temperature of a material is the temperature where the internal friction of the material reaches its maximum value. The local maximum in friction that occurred at approximately $125^{\circ} \mathrm{C}$ for extracted spruce in Fig 7 has previously been presented and proposed to be related to the softening temperature of spruce lignin (Svensson et al. 2006). That proposition was supported by sulfonation trials where spruce wood were treated with sodium sulfite which is known to shift the softening temperature towards lower temperatures proportional to the degree of sulfonation (e.g. Heitner and Atack 1984). This indicate that sometimes internal friction (a bulk property) is closely related to the sliding friction (essentially a surface property). A local maximum was observed for the extracted birch specimens as a small peak in $\mathrm{m}$ at approximately $110-120^{\circ} \mathrm{C}$, but it was not as pronounced 
(see Fig. 7). This local maximum in friction was also present in the results for the native birch specimens (cf. Fig 2). The local maximum seen for the extracted birch specimens is likely related to the softening temperature of birch wood which has been reported to be slightly lower than for spruce wood (e.g. Becker et al. 1977; Olsson and Salmén 1997).

\section{Conclusion}

This study examined the frictional behavior of native and chemically modified birch. Furthermore, the aim was to determine whether the friction could in any way be correlated to the energy consumed when manufacturing birch CTMP. Previous knowledge of the frictional behavior of spruce served well for comparative purposes.

It can be concluded that birch wood differs noticeably from spruce. This study showed that, in general, the friction between birch and steel is higher than the friction between spruce and steel, except at the highest temperature, $\sim 170^{\circ} \mathrm{C}$, at which the curves coincide. The high stiffness and density of the birch wood, together with its more porous bulk structure leading to rough test surfaces, are some possible explanations of the higher friction coefficients reported here. Also, the difference in the composition and location of birch versus spruce extractive substances, and consequently, in their ability to form a lubricating layer, may also contribute to the frictional behavior.

Chemical modification of birch wood had a great impact on the frictional forces in the studied temperature range. Extraction caused the coefficient of friction to rise, which was proposed to be an effect of less lubrication by extractive substances. In addition, the friction coefficient was probably increased by the higher moisture content in the extracted specimens. Treatments with liquor of high $\mathrm{pH}$ lowered the coefficient of friction despite the increased moisture content, possibly due to more efficient lubrication between the steel disc and the wood specimen at high $\mathrm{pH}$. Sulfonating the birch specimens at high $\mathrm{pH}$ gave an increase in $\mu$ at temperatures between $130^{\circ} \mathrm{C}$ and $150^{\circ} \mathrm{C}$. It was suggested that this local maximum partly accounted for the reduced energy consumption reported when the pre-heating temperature is increased when producing birch CTMP.

Knowledge of the frictional behavior between wood and steel is lacking, which complicates the interpretation of the results of this study. A future challenge that could facilitate such interpretation would be measurements of wood performance at high strain rates. Such information can be achieved by using the split Hopkinson pressure bar testing technique. An experimental set-up for such measurements is now being developed at the Mid Sweden University. Linking information from these high strain rate compression tests in a hot steam environment to both frictional behavior and authentic refining trials would be a powerful tool for gaining new insight into the chip refining area.

\section{Acknowledgements}

The financial support of the Swedish Energy Agency, the Swedish Knowledge Foundation, and the European Union (Objective 1) is gratefully acknowledged. The authors would like to thank Dr. Mats Rundlöf for valuable comments on both the experimental work and the manuscript.

\section{Literature}

Atack, D. and May, W.D. (1958): Frictional mechanisms in the grinding process, Pulp Paper Mag. Can. 59 (C), 265-271.

Baek, D.K. and Khonsari, M.M. (2006): Fretting behavior of a rubber coating: Friction characteristics of rubber debris, Wear, 261(10), 1114-1120.

Becker, H., Höglund, H. and Tistad, G. (1977): Frequency and temperature in chip refining, Paperi Puu, 59(3), 123-130.

Bohn, W.L. and Sferrazza, M.J. (1989): Alkaline peroxide mechanical pulping, a revolution in high yield pulping, International Mechanical Pulping Conference, Helsinki, Finland, 184-200.

Granfeldt, T. (2005): The development of emerging markets and use of hardwoods, International Mechanical Pulping Conference, Oslo, Norway, 14-18.

Granfeldt, T., Falk, B., Denton, R. and Åkerlund, G. (2001): Aspen CTMP Where is it now and where is it heading? International Mechanical Pulping Conference, Helsinki, Finland, 315-327.

Granfeldt, T. and Suhonen, V. (2003): The basics of hardwood BCTMP, Fiber and Paper, 5 (1), 40-43.

Heitner, C. and Atack, D. (1984): Dynamic mechanical properties of sulphite treated aspen, Paperi Puu, 66(2), 84-89.

Jackson, M., Åkerlund, G. and Falk, B. (1985): High yield pulp from North American aspen, International Mechanical Pulping Conference, Stockholm, Sweden, 170-185.

Jackson, M., Åkerlund, G. and Höglund, H. (1984): Chemimechanical pulp from aspen shows promise for several grades, Pulp \& Paper, 58(9), 230-232.

Janson, J. and Mannström, B. (1981): Principles of chemical pretreatment in the manufacture of CMP and CTMP from hardwood, Pulp Paper Can. 82(4), 51-63.

Katz, S., Liebergott, N. and Scallan, A.M. (1981): A mechanism for the alkali strengthening of mechanical pulps, Tappi, 64(7), 97-100.

Koran, Z. (1980): Energy consumption in mechanical fibre separation as a function of temperature, 66th Annual Meeting of the Technical Section, CPPA, Montreal, 40-44

Marton, R., Tsujimoto, N. and Eskelinen, E. (1981): Energy consumption in thermomechanical pulping, Tappi, 64(8), 71-74

Miles, K.B. and May, W.D. (1990): The flow of pulp in chip refiners, J. Pulp Paper Sci. 16(2), J63-J72.

Olsson, A.-M. and Salmén, L. (1997): The effect of lignin composition on the elastic properties of wood, Nord. Pulp Paper Res. J. 12(3), 140-144.

Sundholm, J. (Ed) (1999): Raw materials, Ch. 5 in Mechanical pulping Vol. 5 of Papermaking Science and Technology, Finnish Paper Engineers' Association, Helsinki, Finland, 75-83.

Svensson, B., Nyström, S., Gradin, P., Bergfors, E. and Höglund, H. (2003): Tribology under refining conditions: Initial studies, International Mechanical Pulping Conference, Quebec, Canada, 233-237.

Svensson, B., Rundlöf, M. and Höglund, H. (2006): Sliding friction between wood and steel in a saturated steam environment, J. Pulp Paper Sci. 32(1), 38-43.

Vesterlind, E.-L. and Höglund, H. (2005): Chemithermomechanical pulp made from birch at high temperature, SPCI International Conference, Stockholm, Sweden. Vesterlind, E.-L., Kolar, M., Bergström, J. and Höglund, H. (2005): Low energy birch CTMP in bulky paper products, International Mechanical Pulping Conference, Oslo, Norway, 119-125.

Vikman, K., Leskelä, M., Pekkola, M., Vuorio, P., Tyrväinen, J. and Huhtanen, J.P. (2003): New refiner segments technology to optimize the aspen BCTMP pulping process, International Mechanical Pulping Conference, Quebec, Canada, 91-95.

Wegner, T.H. (1982): Improve strength in high-yield pulps through chemical treatment, Tappi, 65(8), 103-107.

Xu, E.C. (1999): A new concept in alkaline peroxide refiner mechanical pulping, International Mechanical Pulping Conference, Houston, USA, 201-211.

Xu, E.C. (2001): P-RC alkaline peroxide mechanical pulping of hardwoods. Part 2: Asian tropical hardwoods, Appita J. 54 (6), 527-531. 